\title{
LEGITIMAÇÃO PELA DETURPAÇÃO: A SUBVERSÃO DO DISCURSO FEMINISTA COMO JUSTIFICATIVA PARA O ENCARCERAMENTO
}

\author{
Natália Lucero Frias Tavares* \\ Antonio Eduardo Ramires Santoro**
}

Resumo: A metodologia adotada ao longo do estudo combinará a pesquisa bibliográfica à análise qualitativa das respostas dadas a questionários sobre execução penal (aplicados entre 2016 e 2017 nas cidades de Petrópolis e Rio de Janeiro), bem como ao estudo dos casos de Barbara Oliveira de Souza e Adriana Ancelmo com o propósito de verificar se há compatibilidade entre o modelo de política criminal implementado, os princípios penais e os direitos e garantias fundamentais.

Palavra-chave: Encarceramento feminino; prisão; criminologia crítica; política criminal; transcendências da pena.

\section{LEGITIMACY THROUGH PERVERSION: THE SUBVERSION OF THE FEMINIST SPEECH AS A MEAN TO JUSTIFY INCARCERATION}

Abstract: Study on the subject of female incarceration and the expansion of criminal law. Allying bibliographical research, qualitative analyses of data gathered through the application of questionnaires (from 2016 until 2017 in the cities of Rio de Janeiro and Petrópolis) and analyses of the Barbara Oliveira de Souza's and Adriana Ancelmo's cases, the article aims to verify if the penal execution structure is compatible with the penal principals and the protection of fundamental rights.

Keywords: Female incarceration; prison; critical criminology; criminal policy; transcending effects of the incarceration.

\footnotetext{
* Mestranda em Direito da Universidade Católica de Petrópolis. Bolsista CAPES. Pós-graduada em Direito e Processo Penal e Criminologia pela Universidade Cândido Mendes (2014) e graduada em Direito pela Universidade do Estado do Rio de Janeiro (2011). Advogada criminalista e pesquisadora. Email: <natalialuceroadv@gmail.com>. Currículo Lattes: lattes.cnpq.br/0410822851348833. Cadastro ORCID: orcid.org/0000-0002-0153-1298

** Professor Titular de Direito Processual Penal do IBMEC/RJ. Professor Adjunto de Direito Processual Penal e Prática Penal da Faculdade Nacional de Direito da Universidade Federal do Rio de Janeiro - FND/UFRJ. Professor Adjunto do Programa de Pós-Graduação em Direito (Mestrado) da Universidade Católica de Petrópolis - UCP. Coordenador do Grupo de Pesquisa "O Sistema Penal sob Olhar Crítico" da UFRJ/UCP. Pós-Doutor em Direito Penal e Garantias Constitucionais pela Universidad Nacional de La Matanza - Argentina. Doutor e Mestre em Filosofia pela UFRJ. Mestre em Direito Penal Internacional pela Universidad de Granada - Espanha. Especialista em Direito Penal Econômico pela Universidade de Coimbra - Portugal. Especialista em Direito da Economia pela Fundação Getúlio Vargas. Graduado em Direito pela UERJ. Licenciando em História pela UNIRIO. Advogado criminalista. Email: <antoniosantoro@antoniosantoro.com.br>. Currículo Lattes: lattes.cnpq.br/9190879263950156. Cadastro ORCID: orcid.org/0000-0003-4485-844X
} 


\section{INTRODUÇÃO}

Em suas primeiras lições de Direito Penal, os estudantes de graduação são introduzidos aos princípios responsáveis por nortear a criação e aplicação de suas normas. Termos como "subsidiariedade", “intervenção mínima" e "lesividade" são apresentados em salas de aula e páginas de livros como características indissociáveis do sistema penal.

Na contramão do ensino jurídico, contudo, é possível constatar a demanda social por leis penais mais severas, práticas menos garantistas e movimentação da estrutura penal como um todo. Esse clamor proveniente de parcela considerável da população acaba por manter um relacionamento simbiótico com práticas como o ativismo judicial e legislativo, bem como com o tom punitivista entoado por diversos outlets midiáticos.

Em suma, essa demanda por utilização mais dura e constante da máquina penal parece fundar-se, em grande parte, na crença popular de que a criminalidade decorre diretamente da impunidade, sendo esta concebida como a escassez de punições ou sua brandura.

As estatísticas do sistema prisional brasileiro parecem, contudo contradizer aquilo que apregoam os defensores das funções preventivas da pena e adeptos do "discurso da impunidade": o país ocupa hoje a terceira posição no ranking mundial em relação ao número de pessoas encarceradas. Perdendo apenas para Estados Unidos e China ${ }^{1}$, o país conta com uma população carcerária que, segundo dados provenientes do último levantamento nacional (que faz referência ao ano de $2014^{2}$ ), ultrapassa a monta de 622 mil pessoas presas e segue em franco crescimento.

O presente estudo pretende abordar especificamente uma das faces do encarceramento brasileiro: o encarceramento feminino. Ainda que, à primeira vista, o número de mulheres presas pareça quase diminuto quando comparado à quantidade de homens privados de liberdade, salta aos olhos a sua taxa de crescimento: no período de 2000 a 2014, o número de

\footnotetext{
${ }^{1}$ Em 2014, último levantamento realizado a nível nacional em relação aos números do sistema prisional, o Brasil contava com 622.202 pessoas presas, o que lhe relegava à quarta colocação no ranking dos países que mais encarceram. Contudo, tendo em vista que a população prisional da Rússia, que, em 2014, era a terceira maior do mundo, tem hoje, segundo dados de $1^{\circ}$ de maio de 2017 (vide Institute for Criminal Policy Research - ICPR/World Prison Brief Data), um total de 622.079, é possível afirmar que, de acordo com os dados disponíveis, o Brasil tem atualmente a terceira maior população prisional do mundo.

${ }^{2}$ Todos os dados foram retirados do Informativo do Sistema Penitenciário publicado no ano de 2015 e referente aos dados de 2014 e servirão de base para o presente estudo em virtude da inexistência de levantamentos nacionais mais atualizados.
}

Rev. de Criminologias e Políticas Criminais | e-ISSN: 2526-0065 | Maranhão | v. 3 | n. 2 | p. 68 - 83 | Jul/Dez. 2017 
mulheres encarceradas saltou de 5.601 para 37.380, representando um aumento percentual de $567 \%$.

Acrescenta-se, ainda, que $30 \%$ destas mulheres hoje presas ainda aguardam julgamento.

Nesta ocasião, busca-se verificar se a política segurança pública ora utilizada guarda uma relação de compatibilidade com as normas vigentes, os princípios que guiam a lei penal e a estrutura estabelecida pela Constituição Federal de 1988. Para tanto, este artigo aliará a pesquisa bibliográfica à empírica, consistindo esta última na análise qualitativa de respostas a questionários referentes ao tema da execução penal aplicados no período de maio de 2016 a abril de 2017 nas cidades do Rio de Janeiro e Petrópolis.

Em sequência, dois casos emblemáticos da atualidade serão apresentados de forma crítica: (i) o caso de Barbara Oliveira de Souza, que deu à luz a seu bebe sozinha enquanto estava no isolamento da Penitenciária Talavera Bruce em 11 de novembro de 2015; (ii) o caso de Adriana Ancelmo que, após recorrer ao Superior Tribunal de Justiça, conseguiu a conversão de sua prisão preventiva em prisão domiciliar por ser mãe de jovem menor de 12 anos.

Com base nos dados analisados, pretende-se oferecer alternativas de fácil implementação para fins de humanização do modelo de execução penal brasileiro bem como apontar possíveis falhas estruturais.

\section{PUNITIVISMO E DIREITO PENAL COMO PRIMA RATIO}

Guiada pela grande mídia, uma enorme parcela da sociedade brasileira rendeu-se ao discurso em prol da elaboração de leis penais mais severas e aplicação de penas elevadas aos condenados, vislumbrando nesse recrudescimento do sistema penal uma chance de alcançar as tão sonhadas "paz social" e "segurança". Nesse contexto, o discurso carente de comprovação empírica que associa a prática delitiva à "certeza de impunidade"3, muitos acreditam ainda na efetividade das - já esvaziadas - funções preventivas da pena.

\footnotetext{
${ }^{3}$ Emprega-se aqui a expressão "certeza de impunidade" entre aspas como referência ao significado que lhe é popularmente atribuído pelos adeptos do expansionismo penal, qual seja a noção de que indivíduos delinquem por acreditar que não serão punidos ou, caso o sejam, que receberão uma punição leve. Importante apontar que tal posicionamento não encontra qualquer semelhança ou proximidade com aquilo que se busca estabelecer ao longo deste ensaio.
}

Rev. de Criminologias e Políticas Criminais | e-ISSN: 2526-0065 | Maranhão | v. 3 | n. 2 | p. 68 - 83 | Jul/Dez. 2017 
Vivemos em tempos de processo penal do espetáculo, nos quais investigações possuem mais fases e audiência que novelas e notícias de crime são unanimidade desde folhetins e telejornais até redes sociais e sites de internet.

Buscando suprir (e fomentar) a demanda diária pelo recrudescimento do sistema penal, a grande mídia, por meio da manipulação da pauta e do discurso, alardeia a ameaça às "pessoas de bem" trazidas pela criminalidade: colocam a impunidade e falta de severidade no tratamento penal como causas dos crimes e criam inimigos públicos.

Seguindo a pauta novelística-midiática, juízes são pintados de heróis (quando se posicionam favoráveis à sanha punitiva); vítimas têm sua vida e privacidade devassadas em prol do interesse público - voyeurístico - nas informações; e acusados, salvo raríssimas (e discricionárias) exceções, são apresentados como indivíduos maus e perversos que mais se assemelham a uma espécie de caricatura lombrosiana.

Toda esta propaganda contribui para um claro processo de desinformação que fortalece e aparelha os setores mais reacionários da sociedade, angariando apoio popular e institucional em prol do agigantamento da - já inflada - máquina penal. Nesta toada, os direitos e garantias fundamentais vão sendo alçados à condição de "obstáculos à justiça e paz social”.

Em resposta a essa demanda originada do senso comum punitivo, inúmeros são os casos em que se observa a prática de ativismo tanto por parte do Poder Legislativo quanto do Judiciário. Contrariando de modo flagrante não apenas os princípios que fundamentam a estruturação do sistema legal brasileiro, mas também os planos traçados pelo legislador constitucional ao consagras direitos e garantias fundamentais, as posturas adotadas pelos Poderes acaba por provocar claro aumento nos processos de criminalização.

Ainda que o número de crimes cometidos e a "sensação de insegurança" não tenha sofrido nenhuma queda frente ao aumento de prisões, a revisão da estrutura prisional e/ou utilização de vias alternativas para resolução de conflitos estão longe de se tornar realidade.

Nesta esteira, o que se observa é uma grave desconsideração - ou, por vezes, patente negação - daquilo que apregoam os princípios adotados pelo ordenamento pátrio e que deveriam constituir a própria essência indissociável do direito penal. Diferentemente do que ocorre com o direito civil ou administrativo, o direito penal apenas deveria incidir nas ocasiões em que os

Rev. de Criminologias e Políticas Criminais | e-ISSN: 2526-0065 | Maranhão | v. 3 | n. 2 | p. 68 - 83 | Jul/Dez. 2017 
demais se demonstrassem incapazes de pôr fim ao conflito, ou seja, com caráter subsidiário, fragmentário: a ultima ratio.

Ao abordarem a importância dos princípios para a estruturação do direito penal no capítulo IV do tomo I da obra Direito Penal Brasileiro, os autores Batista, Zaffaroni, Allagia e Slokar dividem-nos em três grupos: (i) princípio da legalidade, com todos os seus desdobramentos formais que afetam diretamente a vigência, redação e interpretação da norma penal; (ii) princípios limitadores que excluem violações ou disfuncionalidades grosseiras com os direitos humanos, ou seja, os princípios que auxiliam no processo de compatibilização da norma penal com a observância e tutelo dos direitos e garantias fundamentais, por exemplo, princípios da lesividade, proporcionalidade mínima, intrascendência, etc.; (iii) princípios limitadores da criminalização que emergem diretamente do princípio do estado de direito.

No momento em que os aplicadores da lei penal a interpretam e aplicam de maneira expansiva, ampliativa, estamos diante de um agigantamento injustificado e inconstitucional do direito penal. O mesmo ocorre quando no momento da criminalização primário o legislador opta por conferir tratamento penal a bem jurídicos que não deveriam ser tutelados por esta via ou decide, por exemplo, sucumbir à demanda popular por penas mais severas.

Estes episódios de ativismos judiciais e legislativos, cada vez mais corriqueiros na seara criminal, acabam por deslocar o âmbito de atuação do direito penal, revertendo-o de ultima a prima ratio, atentando claramente contra os desejos do constituinte originário e as próprias bases do estado democrático de direito.

E neste contexto de banalização das fases da criminalização, antagônico aos ideias abolicionistas e reducionistas do direito penal e demasiadamente distante do modelo garantista de Ferrajoli e repleto de violações aos direitos e garantias fundamentais, o presente artigo propõe um recorte temático específico: uma análise dos impactos do expansionismo penal sobre a figura da mulher.

Neste ponto, importante atentar para a estreita relação mantida entre o encarceramento feminino e um dos princípios norteadores da aplicação da lei penal: o princípio da intrascendência da pena. 


\section{O ENCARCERAMENTO FEMININO E AS TRANSCENDÊNCIAS DA PENA}

Ao tratar dos objetivos do Direito Penal em suas obras, Juarez Cirino dos Santos faz uma clara distinção entre os denominados "objetivos declarados" e os velados (seus efetivos desdobramentos), apontando a grande intersecção existente entre este ramo do direito e a desigualdade social. Afirma o autor (SANTOS, 2014. p.10) :

"O significado político do controle social realizado pelo Direito Penal e pelo Sistema de Justiça Criminal aparece nas funções reais desse setor do Direito - encobertas pelas funções declaradas do discurso oficial: a criminalização primária realizada pelo Direito Penal (definição legal de crimes e de penas) e a criminalização secundária realizada pelo Sistema de Justiça Criminal constituído pela polícia, justiça e prisão (aplicação e execução de penas criminais) garantem a existência e a reprodução da realidade social desigual das sociedades contemporâneas".

Cirino dos Santos chama atenção para a maneira como o Direito Penal - por meio da criminalização de determinadas condutas - atende aos interesses das classes sociais hegemônicas, assegurando a manutenção de seu status quo.

O processo de criminalização primária traduz claramente as escolhas de política criminal de seu local de inserção em virtude da natureza dos bens jurídicos tutelados: inexistindo em nosso ordenamento qualquer direito absoluto ${ }^{4}$ ou ordem de importância e prevalência pré-estabelecidas, o ato de conferir proteção penal a determinado bem jurídico não é automático ou óbvio, mas uma construção.

A análise das estatísticas prisionais não deixa dúvida quanto aos bens jurídicos que mais recebem proteção da tutela penal na atualidade: as maiores causas para aplicação de pena privativa de liberdade no Brasil de hoje é (i) a prática de crimes contra o patrimônio ou (ii) relacionados ao comércio ilegal de drogas. Essa constatação diz muito sobre a sociedade brasileira, as relações de disparidade econômica que naturalizam a supressão da liberdade em prol da proteção patrimonial e a adesão ao modelo de política criminal de guerra às drogas.

\footnotetext{
${ }^{4}$ Nenhum direito - ainda que garantido por cláusula pétrea - é absoluto. Deste modo, sempre que diferentes direitos ou garantias colidem não existe uma ordem pré-determinada de prevalência ou sacrifício, demandando a realização de um estudo do caso concreto para determinar qual deverá prosperar naquela hipótese específica. Nem mesmo o direito à vida é absoluto, sendo admitida pena de morte nas hipóteses do inciso XLVII, alínea "a" do art. $5^{\circ}$ da CRFB/88.
}

Rev. de Criminologias e Políticas Criminais | e-ISSN: 2526-0065 | Maranhão | v. 3 | n. 2 | p. 68 - 83 | Jul/Dez. 2017 
Em função da escassez de tempo e espaço adequado para realização de uma análise profunda sobre os fatores que contribuem para esse modelo de criminalização como ferramenta de controle e opressão, a análise destes dados será abordada à luz do recorte proposto, qual seja: o aprisionamento de mulheres.

A principal causa para o encarceramento feminino nos dias atuais é a prática de crimes relacionado ao comércio ilegal de drogas. Por receber tratamento equiparado àquele dado aos crimes hediondos, condenações desta natureza configuram sinônimo de uma permanência mais extensa das apenadas dentro dos limites físicos do sistema prisional em virtude das frações mais elevadas exigidas para fin de progressão de regime de cumprimento de pena, concessão de livramento condicional e impossibilidade de recebimento de comutação de pena.

Retomando a análise dos princípios adotados pelo ordenamento pátrio, merece especial menção o princípio da pessoalidade, personalidade ou intranscendência da pena que, em pouca palavras, determina que a pena não deve atingir terceiros, ou seja, não deve transcender a pessoa do condenado. Contudo, a estruturação do modelo de execução penal não convive harmonicamente com tal limitação.

Muitos são os exemplos de efeitos decorrentes do encarceramento que atingem a esfera de direitos de terceiros. Exemplos claros disso são o afastamento do convívio familiar; os impactos econômicos para custeio da estrutura prisional; no caso de grávidas encarceradas, a colocação do feto em condições insalubres para manutenção de uma gestação e privação de convívio prolongado com a mãe nas primeiras etapas da vida, dentre tantas outras circunstâncias.

Considerando a relevância da presença da figura materna para fins de desenvolvimento de jovens e crianças (sem negar de maneira alguma, por via de consequência, a relevância da presença paterna), aduz-se que o encarceramento feminino traduz-se como sinônimo de atingimento de terceiros e, portanto, inconstitucional.

A escolha de iniciar a análise das violações a princípios decorrentes do modelo de encarceramento feminino pelo princípio da instrancendência da pena não se deu ao acaso e sim pelos seguintes fundamentos: (i) a insuperável contradição entre o princípio da pessoalidade da pena e o encarceramento de crianças; (ii) o crescimento exponencial das cifras de encarceramento feminino, em grande parte fruto da seletividade punitiva da (fracassada) 
política de guerra às drogas ${ }^{5}$ nesta sociedade marcada pelo patriarcado e colonialismo; (iii) os graves desdobramentos que tal estruturação de cumprimento de pena traz para a sociedade em sua integralidade, não se limitando de forma alguma às mulheres e crianças diretamente atingidas pela pena; (iv) os preocupantes resultados quantitativos e qualitativos obtidos quando da aplicação dos questionários dirigidos à análise empírica; (v) a necessidade de denunciar e rebater o machismo que impregna tanto a estrutura prisional, quanto o ideário popular construído desprovido de empiria.

Assevera-se, portanto, que manutenção de grávidas e infantes no ambiente prisional merece detida análise em decorrência da pluralidade de críticas e contradições legais que abrange, sendo estas muito mais amplas e profundas que a mera análise de legalidade da prática.

Propõe-se aqui uma pequena provocação decorrente da análise global do sistema penal: o manutenção de gestantes em ambiente prisional não poderia ser interpretada como um ato estatal que expõe a perigo não apenas a interna, mas também o desenvolvimento da gestação e, por conseguinte, nascimento com vida e saúde?

\section{A DETURPAÇÃO DA LUTA FEMINISTA COMO FERRAMENTA DE OPRESSÃO}

Buscando compreender o posicionamento social a respeito da coexistência entre os direitos e garantias fundamentais que legitimam a criminalização do aborto com a possibilidade de aplicação de pena privativa de liberdade a mulheres gráficas, optou-se pela realização de pesquisa empírica pela via de aplicação de quetionários.

Sendo certo que a análise qualitativa dos dados coletados ao longo da aplicação dos questionários demonstra-se mais frutífera para o prosseguimento do presente estudo, fazem-se oportunos comentários sobre a metodologia adotado. Ao longo do período que vai de maio de 2016 a abril de 2017, 526 questionário foram aplicados pessoalmente pelos autores nas nas cidades de Rio de Janeiro e Petrópolis.

\footnotetext{
${ }^{5}$ Como bem demonstram as obras da autora e professora Luciana Boiteux e os índices da Rede Justiça Criminal, os impactos da política de guerra às drogas são gravíssimos e indissociáveis da elevação exponencial no número de mulheres encarceradas hoje no Brasil, sendo certo, contudo, que a vasta maioria destas apenadas ocupa posição de pouco ou nenhum poder em relação ao esquema de comercialização de drogas.
} 
Os questionários eram formados por uma série de perguntas atinentes a questões relevantes na temática da execução penal com o propósito de coletar dados quantitativos a respeito de determinadas proposições.

Dentre as perguntas realizadas ao longo do questionário, uma possuía o seguinte enunciado: "o que acha da aplicação de pena de prisão para gestantes condenadas ${ }^{6}$ pela prática de crimes". A pergunta comportava três opções de respostas para fins de quantificação: contrário(a); favorável; não tem opinião formada sobre o tema. Além de solicitar que o entrevistado selecionasse uma dentre as três opções, lhe era fornecido espaço e tempo para que, se desejasse, fizesse breves comentários sobre a pergunta.

Ainda que as estatísticas (análise quantitativa) obtidas através da aplicação dos questionários já cause fundado temor naqueles que defendem um modelo minimalista de sistema penal, um dos dados que mais causou surpresa aos aplicadores foram as fundamentações fornecidas pelos entrevistados para justificação do posicionamento adotado em prol do encarceramento de mulheres durante o período gestacional.

Ressalta-se que nas ocasiões em que era facultado ao entrevistado responder ao questionário por escrito, apenas aqueles que manifestaram-se contrários à prisão de gestantes forneceram justificativas para sua resposta. Tais fundamentações seguiam basicamente os seguintes padrões: (i) prender gestante fere dignidade; (ii) colocação da gestação em perigo; (iii) aplicação da pena deve ocorrer apenas após o parto. Alguns destes entrevistados falavam que apenas seriam contrários se a prática do crime não tivesse ocorrido durante a gestação.

Nas hipóteses de aplicação direta pelos entrevistadores, ocasião em que os entrevistados deveriam informar seu posicionamento verbalmente, aqueles contrários ao encarceramento de gestantes ofereçam o mesmo padrão de resposta anteriormente mencionado.

Contudo, o padrão de reação daqueles que se manifestaram favoráveis ao encarceramento de gestantes condenadas pela prática de crimes apresentou modificação (especialmente nas hipóteses em que a entrevista era conduzida por uma mulher).

Dentre as justificativas apresentadas, as respostas mais constantes foram: (i) quem comete crime tem que pagar pelos seus atos; (ii) se gestantes não puderem ser encarceradas,

\footnotetext{
${ }^{6}$ A pergunta se dirigia diretamente à temática do encarceramento de mulheres grávidas, por tal motivo, neste item específico do questionário optou-se por fazer referência apenas àquelas mulheres que já tivessem recebido efetiva condenação, não adentrando neste ponto a problematização a respeito da execução antecipada de pena em momento anterior ao trânsito em julgado. Tal opção metodológica justificou-se por permitir um estudo mais objetivo da temática do encarceramento de gestantes.
} 
todas as presas começaram a engravidar para fugir da pena e/ou criminosos utilizaram grávidas para cometimento de crimes; (iii) respostas pautadas numa inversão dos discursos feministas como ferramenta para justificação do encarceramento.

Importante ressaltar que o terceiro tipo de resposta apenas foi apresentado em hipóteses em que o questionário era aplicado por entrevistadoras e respondido por homens e superam o percentual de $5 \%$ do total de entrevistados.

Foram exatamente estas resposta que serviram de estopim para o nascimento do presente trabalho. Ao tentarem justificar sua concordância com este modelo de política criminal, os entrevistados alegavam que as conquistas do feminismo não poderiam ser negadas, ou seja, o pleito feminino por tratamento igualitário deveria ser respeitado, o que legitimaria a aplicação da pena de prisão mesmo durante o período gestacional.

Nesta ginástica argumentativa, as expressões mais utilizadas foram "direitos iguais para todos", "não discriminar mulheres com tratamento diferenciado" e "respeitar o papel da mulher como tão capaz quanto o homem”.

A resposta que mais causou espanto nos entrevistadores foi dado por um estudante da Fundação Escola Superior da Defensoria Pública em outubro de 2016. O mesmo afirmou "as mulheres passaram as últimas décadas buscando respeito aos seus direitos. Deixar de prender a mulher só porque ela está grávida é o mesmo que dizer que ela é fraca, é machismo. Só porque homem não engravida não é desculpa para tratar de maneira desigual”.

O que se observa por traz deste esforço retórico dos entrevistados é um claro desejo de demonstrar-se humanitário e favorável aos direitos da mulher ao mesmo tempo que (sabidamente ou não) entoa um discurso machista, opressor.

\section{OS CASOS DE BARBARA OLIVEIRA DE SOUZA E ADRIANA ANCELMO}

Para melhor ilustrar as hipóteses de transcendência da pena decorrentes da aplicação de pena de prisão e os impactos sociais da política de encarceramento, selecionou-se dois casos emblemáticos ocorridos no Rio de Janeiro em período recente. 


\section{1. $O$ castigo para gestante}

Barbara Oliveira de Souza estava sozinha quando deu a luz a seu bebê em 11 de outubro de $2015^{7}$ em uma cela na solitário do Presídio Talavera Bruce, situado dentro do Complexo de Presídios de Jericinó no Rio de Janeiro. Barbara já estava quase no término de sua gestação quando foi mandada para o isolamento como castigo por seu comportamento ${ }^{8}$. Ao perceberem o que ocorria dentro da cela, detentas de celas vizinhas gritaram, em vão, por socorro.

Por esta ocasião, faz-se oportuno salientar que após ser atendimento em hospital, Barbara voltou ao isolamento e a criança foi encaminhada a um abrigo, mesmo com a penitenciária dispondo de Unidade Materno Infantil (UMI).

Quinze dias após o nascimento de seu bebê, a experiência de Barbara veio a público e causou muitas críticas, tanto por parte do Poder Judiciário quanto pela Comissão de Direitos da Mulher da Assembleia Legislativa do Rio de Janeiro.

\subsection{A revolta popular pelo desempenho do papel materno}

$\mathrm{O}$ caso de Adriana Ancelmo retrata uma realidade bem diferente daquela de Barbara. Casada com o ex-governador do Rio de Janeiro, Sérgio Cabral, Adriana foi presa preventivamente no dia 6 de dezembro de 2016. Em 17 de março de 2017, o juiz da $7^{\text {a }}$ Vara Federal Criminal do Rio, converteu a prisão preventiva em domiciliar.

A decisão de ofício que converteu a prisão de Adriana fundamentou-se no fato de que tanto ela quanto o marido estavam presos, circunstâncias que dificultam a criação dos dois filhos menores do casal, que contam com as idades de 11 e 14 anos. Em resposta, o Ministério Público Federal no Rio de Janeiro impetrou Mandado de Segurança, com pedido de liminar, contra a decisão.

O desembargador do Tribunal Regional Federal da $1^{\text {a }}$ Região concedeu a liminar sob a alegação de que a regra do artigo 318 do Código de Processo Penal não deveria se extender à

\footnotetext{
${ }^{7}$ Apenas dias após o ocorrido foi que o fato veio a público, como evidenciam as reportagens da época, disponível em 〈http://agenciabrasil.ebc.com.br/geral/noticia/2015-10/presa-gravida-da-luz-em-solitaria-de-presidio-no-rio > (acesso em 18/08/2017).

${ }^{8}$ A despeito da negativa por parte da Secretaria de Administração Penitenciária a respeito da aplicação de punição à interna e as circunstâncias em que se operou o parto (alegaram que teriam-na encaminhado à maternidade às pressas antes do nascimento da criança), o juízo da Vara de Execuções Penais declarou que Barbara fora isolada como uma espécie de castigo por suposta agressão cometida e que, segundo declarações das demais internas, já tinha o bebê nos braços mas ainda preso pelo cordão umbilical quando foi retirada da cela.
} 
investigada em decorrência da gravidade dos fatos a ela imputados. Ainda em sede de sua decisão, o desembargador considerou que a decisão beneficiando Adriana criaria expectativas para outras mulheres presas preventivamente, que não conseguem o mesmo direito 9 .

A prisão domiciliar apenas foi restabelecida após julgamento de Habeas corpus impetrado pela defesa de Adriana Ancelmo no Superior Tribunal de Justiça alegando não ser cabível a impetração de MS com a finalidade de conferir efeito suspensivo a recurso em sentido estrito interposto contra decisão concessiva de liberdade e, por conseguinte, da aplicação de medida cautelar pessoal diversa.

Até a presente data, Adriana permanece em prisão domiciliar enquanto seu marido encontra-se preso no Complexo Penitenciário de Bangu.

A conversão da prisão de Adriana Ancelmo provocou forte furor popular por distintas razões, dentre elas duas merecem especial atenção para fins do presente estudo: (i) desejo popular pela imposição da pena como forma de provocar sofrimento; (ii) a desigualdade no tratamento dado às demais mulheres presas.

\subsection{Seletividade, transcendência e função da pena}

São muitas as diferenças que existem entre Barbara e Adriana, seu poder aquisitivo, escolaridade, natureza do crime que lhes foi imputado, a possibilidade de conviver e zelar por seus filhos, dentre tantas outras. Mas duas similaridades são incontestáveis em ambos os casos: a certeza de que os efeitos da pena de prisão ultrapassam a figura do condenado e o sofrimento associado ao cárcere.

Mesmo sem ter cometido qualquer ilícito ou sequer possuir imputabilidade penal, o bebê de Barbara foi gestado em condições insalubres, iniciou sua vida no cárcere e logo em seguida enviado para um abrigo, privado de qualquer convívio familiar. Uma criança que nasceu presa para em seguida, crescer abandona, uma flagrante violação ao princípio da personalidade da pena. Não fosse pela circunstância em que esse nascimento se operou, a história de Barbara e seu bebê seria apenas mais um vírgula no triste cotidiano das mulheres encarceradas no Brasil.

Já em relação à Adriana, a resposta dos meios jornalísticos não se mostrou tão solidária: inúmeras manchetes criticando a clara disparidade no tratamento dado àqueles de

\footnotetext{
9 Notícia detalhada disponível no sítio eletrônico < http://www.conjur.com.br/2017-mar-25/ministra-stj-

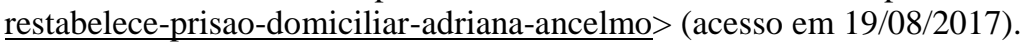

Rev. de Criminologias e Políticas Criminais | e-ISSN: 2526-0065 | Maranhão | v. 3 | n. 2 | p. 68 - 83 | Jul/Dez. 2017 
classes mais abastadas mesmo em momentos de persecução penal e cumprimento da pena e a revolta de elevada parcela da população fluminense, revoltada diante dos escândalos de corrupção envolvendo a investigada e seu marido que contribuíram para a crise do Estado do Rio de Janeiro.

Na realidade, o tratamento dado à Adriana deveria ter sido dispensado também à Barbara. É neste ponto que as características econômicas que as diferenciam também atingem sua prole: os filhos de Adriana, que nenhuma responsabilidade possuem em relação a crimes que seus genitores possam ou não ter cometido, não devem ser punidos por tais circunstâncias.

Em brilhante parecer elaborado a pedido da Clínica de Direitos Humanos da Universidade do Estado do Rio de Janeiro na ADPF 347 em 07/04/2015, o renomado professor Juarez Tavares (2016, p. 464) delineou as mazelas que assolam o sistema carcerário brasileiro e sua incapacidade de cumprir com as funções a que se pretende. Ao abordar a questão da superpopulação, Tavares escreve:

\footnotetext{
"As propostas concretas de superação do grave problema da superpopulação carcerária - agravado pela sistemática violação da dignidade da pessoa humana e de direitos correlatos - passam necessariamente, ao menos na quadra atual, pela adoção de um princípio geral de flexibilidade da pena. Como o Estado, nas condições materiais atuais, não garante ao detento os direitos fundamentais dos presos, não há dúvida quanto à necessidade de amenizar o rigor das exigências legais para o deferimento de benefícios da execução da pena. Só assim será possível interromper, com a rapidez necessária, o atual quadro de sistemática violação de direitos fundamentais".
}

Seguindo as lições de Juarez Tavares, parece acertado defender um modelo de cumprimento de pena que não se dirija à opressão dos apenados, mas sim que observe a tutela de seus direitos e garantias fundamentais. Deste modo, no momento em que a negativa de um direito de uma pessoa presa se pauta no fato de que "se concedido seu pleito, outros também irão demandá-lo" aparenta ter tom jocoso, uma vez que liberdade deve ser a regra imperante.

\section{CONSIDERAÇÕES FINAIS}

Ao longo da história, a consagração da pena de prisão ocorreu no momento em que se constatou que o encarceramento permitia a exploração da força da mão de obra aprisionada, sendo a pena uma clara ferramenta de controle social e, mesmo, de produção de riqueza. 
Contudo, a pena nos dias de hoje mais se traduz como efetiva ferramenta de neutralização: retira-se do convívio social aqueles indivíduos

No momento em que o legislador decide quais bens jurídicos serão penalmente tutelados e quais serão as penas cabíveis em caso de violação, está fazendo, antes de qualquer coisa, uma escolha política. A criminalização primária não é, portanto, imune a paixões, pressões econômicas ou políticas. Por tais razões, faz-se mister uma avaliação crítica do sistema penal e da estrutura político-econômica vigente.

A seletividade que marca a aplicação da lei penal é uma constante no cenário prisional brasileiro e vem acompanhada de outro fator alarmante: a superlotação carcerária - em parte resultante da política de guerra às drogas e do encarceramento da pobreza ocasionado pela exacerbada proteção conferida ao direito à propriedade

Sendo certo que o contingente carcerário brasileiro, a despeito da heterogeneidade de sua população, apresenta um aspecto homogeneizado, ocupado por aqueles que se enquadram na chamada categoria de "clientes habituais do sistema penal", é possível constatar a existência de seletividade na aplicação - e, também, na própria criação da norma incriminadora.

Mesmo que cumprida em condições de total humanidade e respeito, a pena de prisão constitui não apenas uma simples privação da liberdade ambulatorial dos indivíduos, sendo sinônimo de privação de convívio com seus familiares e garantia do estigma de egresso do sistema prisional, consagrando-se como ferramenta para punição causadora de sofrimento.

No contexto prisional brasileiro, a execução penal configura verdadeiro martírio, afastando-se por completo dos supostos ideais de reintegração, ressocialização e todos as demais apregoadas funções "re" que se possa mencionar. Cumprida em ambiente superlotado e insalubre no qual a falta de espaço só não é menor que a falta de condições dignas de subsistência, a pena de prisão no Brasil

A estruturação do estado democrático de direito calca-se não apenas na prevalência dos interesses da maioria para tomada de escolhas, mas, principalmente, na proteção dos direitos das minorias, daqueles mais oprimidos.

As conquistas da luta feminina buscam, de modo geral, retirar do corpo e da figura feminina a opressão do patriarcado. No momento em que a luta pelo fim da discriminação diária sofrida pelas mulheres é invocada como justificativa para o aprisionamento de mulheres 
grávidas, se está diante de clara hipótese de deturpação do discurso feminista, uma real dissimulação do opressão travestida de tratamento equânime.

O modelo de cumprimento de pena hoje vigente não possui estrutura adequada para conceder à mulher presa o mínimo de dignidade para sua subsistência: desde a ausência de produtos para higiene íntima à dificuldade em manter contato com suas famílias uma vez que muitas das mulheres hoje encarceradas são mães solteira e, portanto, precisam contar com auxílio de amigos e familiares para que seus filhos sejam cuidados.

Desta forma, pode-se listar como medidas adequadas para minorar os impactos do encarceramento feminino galopante de maneira rápida e efetiva: (i) a vedação do encarceramento de gestantes; (ii) a cumprimento de pena domiciliar para mulheres com filhos menores; (iii) fornecimento de materias de higiene e remédios.

\section{REFERÊNCIAS BIBLIOGRÁFICAS}

BOITEUX, Luciana. Drogas e cárcere: repressão às drogas, aumento da população penitenciária brasileira e alternativas. In: SHECAIRA, Sergio Salomão (Org.). Drogas: uma nova perspectiva. São Paulo: IBCCRIM, 2014.

BRASIL. Levantamento Nacional de Informações Penitenciárias - Infopen - dezembro de 2014. Brasília: Ministério da Justiça, 2016. Disponível em: $<$ http://www.justica.gov.br/noticias/mj-divulgara-novo-relatorio-do-infopen-nesta-tercafeira/relatorio-depen-versao-web.pdf >. Acesso em 15 de junho de 2017.

Supremo Tribunal Federal. ADPF 347 MC/DF. Relator Ministro Marco Aurélio, j. 9.9.2015. Informativos 796, 797 e 798. Disponível em <www.stf.jus.br>. Acesso em 15 de junho de 2017.

ICPR - INSTITUTE FOR CRIMINAL POLICY RESEARCH. World Prison Brief. Universidade de Londres. Disponível em <www.prisonstudies.org>. Acessado em 15 de junho de 2017.

FERRAJOLI, Luigi. Direito e razão: teoria do garantismo penal. 4a ed. Tradutores: Ana Paula Zomer Sica, Fauzi Hassan Choukr, Juarez Tavares e Luiz Flávio Gomes. São Paulo: Revista dos Tribunais, 2014.

QUEIROZ, Nana. Presos que menstruam: a brutal vida das mulheres tratadas como homens nas prisões brasileira. $1^{\mathrm{a}}$ ed. São Paulo: Record, 2015.

SANTOS, Juarez Cirino dos. Direito Penal: Parte Geral. $6^{\text {a }}$ Ed atualizada e ampliada. Curitiba: ICPC Cursos e Edições, 2014. 
WACQUANT, Loic. Punir os pobres: a nova gestão da miséria nos Estados Unidos [a onde punitiva]. Rio de Janeiro: Revan, 2007.

ZACCONE, Orlando. Acionistas do nada: quem são os traficantes de drogas. Rio de Janeiro: Revan, 2007.

ZAFFARONI, Eugenio R; BATISTA, Nilo; ALAGIA, Alejandro; SLOKAR, Alejandro. Direito Penal Brasileiro: primeiro volume - Teoria Geral do Direito Penal. $4^{\mathrm{a}}$ ed. Rio de Janeiro: Revan, 2011. 